\title{
A STUDY OF ADSORPTION OF DAZOMET FROM AQUEOUS SOLUTION ON KAOLIN
}

\section{Inam Hussein Ali \\ Teaching assistant, Chemistry Department, College of Science for Women , Baghdad University}

\section{Abstract :}

In this research, the adsorption of dazomet from aqueous solution on kaolin at $\left(30 \mathrm{C}^{\circ}\right)$ was studied. It was observed that the adsorption was consistent with the Freundlich adsorption isotherm and thus it is evident that the multilayer adsorption takes place from solutions. The adsorption phenomena were investigated with respect to change in concentration, and duration of process. The adsorption rate of dazomet was found to fit the first- order of kinetic equation. Also, the adsorption rate decreased linearly with the initial concentration which evident that the adsorption is controlled by a film diffusion mechanism.

Keywords: kaolin, Dazomet, adsorption from solution, Freundlich isotherm.

\section{Introduction}

Adsorption from aqueous solution on natural materials has been subjects of interest for years. Adsorption on clays plays an important role in the environment by controlling the fate availability of organic compounds because of their adsorption capability which are influenced strongly by constituents that have high specific surface area and highly reactive surfaces ${ }^{(1)}$. On the other hand, clays are much less expensive compared to common adsorbents like activated carbon. Adsorption from aqueous solution to solid surfaces is one of the key processes determining the concentration and rate of transport of pesticide in aquifers ${ }^{(2)}$.

Kaolin is a clay mineral with chemical composition $\mathrm{Al}_{2} \mathrm{Si}_{2} \mathrm{O}_{5}(\mathrm{OH})_{4}$. It's a mixture of different minerals and its main component is kaolinite; in addition, it frequently contains quartz, mica, feldspar, illite, and montomoillonite $^{(3)}$. Kaolin is an excellent adsorbent due to large surface area and highly reactive surfaces. It has been employed to adsorb toxic substances from the alimentary canal and in the treatment of diarrhea associated with food poisoning ${ }^{(4)}$. A. O. Onyekweli et.al ${ }^{(5)}$ have been reported that kaolin can adsorb some active drugs when it use as a lubricant in a tablet formulation. Many studies have been done on the adsorption of pesticides to clays ${ }^{(6-10)}$. They have the greatest potential for adsorption of pesticides due to the large surface area and the functional group of these constituents. Adsorption of eleven well characterized humic substances onto Na-kaolin clay from aqueous solution has been studied ${ }^{(11)}$. The adsorption affinity, maximum adsorption capacity, a coefficient of desorption hysteresis, and the concentration of irreversibility adsorbed were derived from adsorption- desorption isotherms. A.F.El. Aswad ${ }^{(12)}$ studied the sorptiondesorption isotherms of aldicarb and formation of its soil-bound residues in three common Egyptian soil types. The results of this study indicated that its adsorption isotherm forms on clay soil were S-type, while that of calcareous soil, and sandy soil were C-type. Also, adsorption of aldicarb was found to conform to Freundlich equation, and the magnitude of adsorption was found to be in the order:

Clay soil > Calcareous soil > sandy soil.

Dazomet (I) ${ }^{(13)}$, chemically known as $(3,5$ di-methyl tetra-2H-1, 3, 5-thiadizine-2-thione), has been widely used as a pesticide in a variety of setting. In agriculture dazomet has found application as a fungicide, herbicide and nematocide for cabbage, cucumber, maize, potato, and tomato plants ${ }^{(14)}$. 
<smiles>CN1CSC(=S)N(C)C1</smiles>

(I)

The adsorption of dazomet on bentonite and zeolite has been studied at four temperatures and two different solutions (water and water- ethanol mixture) ${ }^{(15)}$.

This study was carried out to study the adsorption isotherm of dazomet solution on the natural Iraqi kaolin clay, and to evaluate the rate of adsorption process of this system.

\section{Experimental}

\section{Apparatus}

1- Computerize UV-Visible, T60U Spectrophotometer, PG Instruments LtD.

2- Centrifuge type ( Remi and R laboratory Centrifuge).

3- Analytical balance type (Sartorious BL 2105).

4- Tube rotator shaker type SATUART (Great Britain).

\section{Kaolin Clay}

Kaolin clay was supplied from the state company for geological survy and mining- Iraq. The chemical composition of kaolin was reported ${ }^{(16)}$ to be $46.5 \% \mathrm{SiO}_{2}, 39.5 \% \mathrm{Al}_{2} \mathrm{O}$, and $14 \% \mathrm{H}_{2} \mathrm{O}$. Kaolin was sieved and the particle size ranged from 150 to $212 \mathrm{~nm}$ were obtained. Before using in adsorption experiments, it was washed with distilled water and dried in an oven at $100{ }^{\circ} \mathrm{C}$ for 2 hours.

\section{Dazomet}

The pure crystalline dazomet used in the adsorption experiments was obtained from Unifert Company -Lebanon, license from PASF Germany with purity of $98 \%$ as a white crystalline solid. A sample of $100 \mathrm{ppm}$ dazomet solution was prepared and a spectrum scan was measured using UV-Visible spectrophotometer and showed a $\lambda \max$ at $280 \mathrm{~nm}$, then the calibration curve was accomplished by measuring the absorbance of solution between the concentration range $(5-50) \mathrm{mg} / \mathrm{L}$.

Figure (1) shows the calibration curve of dazomet.

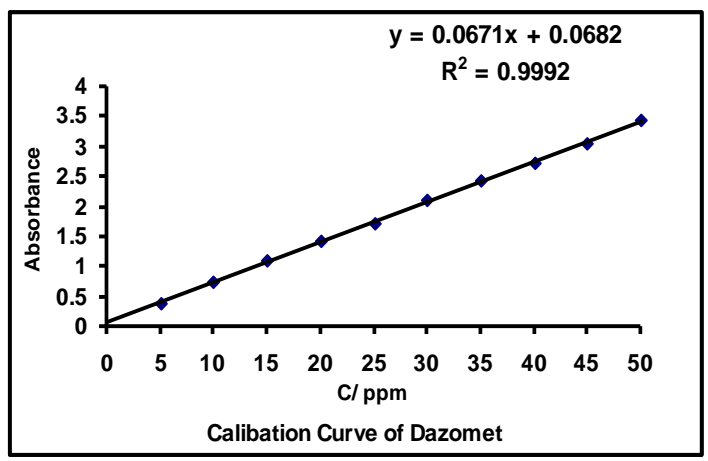

Fig (1): calibration curve of dazomet.

\section{Stock solution}

Stock solution of dazomet for adsorption experiments was prepared in double distilled water on a daily basis as follows:- $0.01 \mathrm{~g}$ of dry sample were dissolved in $50 \mathrm{ml}$ distilled water and volume complete with water in $100 \mathrm{ml}$ volumetType equation here.ric flask. The stock solution was used immediately after preparation.

\section{Adsorption method:}

Adsorption of dazomet was studied using a batch equilibration procedure. Duplicate of $0.3 \mathrm{~g}$ sample of kaolin clay were treated with $10 \mathrm{ml}$ of dazomet solution of concentration ranged from $3 \times 10^{-5}$ to $1 \times 10^{-4} \mathrm{~mol} / \mathrm{L}$. Ten test tubes of the suspension were shaken with tube rotator shaker for five hours. These samples were centrifuged for $10 \mathrm{~min}$ at $4000 \mathrm{rpm}$ (for each sample) within interval of $30 \mathrm{~min}$ between them. The equilibrium concentration of dazomet was determined by UV spectroscopy. The maximum absorbance value at $280 \mathrm{~nm}$ was measured and the amount of adsorbed dazomet was calculated from the differences between initial and equilibrium concentration according to the following equation:-

$$
\mathrm{X}=\frac{\mathrm{V}\left(\mathrm{C}_{\mathrm{o}}-\mathrm{C}_{\mathrm{e}}\right)}{\mathrm{W}}
$$


Where (X) amount of adsorbed dazomet $(\mathrm{mg} / \mathrm{g})$, $\left(\mathrm{C}_{\mathrm{o}}\right)$ the initial concentration of $\operatorname{dazomet}(\mathrm{mg} / \mathrm{l})$, $\left(\mathrm{C}_{\mathrm{e}}\right)$ concentration of dazomet at equilibrium(mg/l), (V) the volume of sample (liter) and (W) weight of kaolin(g).

\section{Results and Discussions}

\section{Equilibrium time and sorbent quantity}

The time required for adsorbate- adsorbent system to reach adsorption equilibrium depends on type of adsorbate and adsorbent characteristics. Therefore, the adsorbability of dazomet from solution of various concentrations on kaolin clay was studied as a function of time to determine the time needed for equilibration. The results obtained are illustrated in figure (2). The figure shows that the time needed to obtain equilibrium value was 4 hours at all the concentrations used in this work. Based on this result, an equilibrium time of 4 hours used in subsequent adsorption experiments.

On the other hand, the influenced of kaolin clay amount on the adsorption process has been investigated employing different amounts of kaolin clay varying from 0.1 to $0.5 \mathrm{~g}$ with $10 \mathrm{ml}$ of the same concentration of dazomet ( $1 \times 10^{-4}$ mol/ Liter). The plot of amount of dazomet adsorbed against kaolin clay quantity was shown in figure (3).

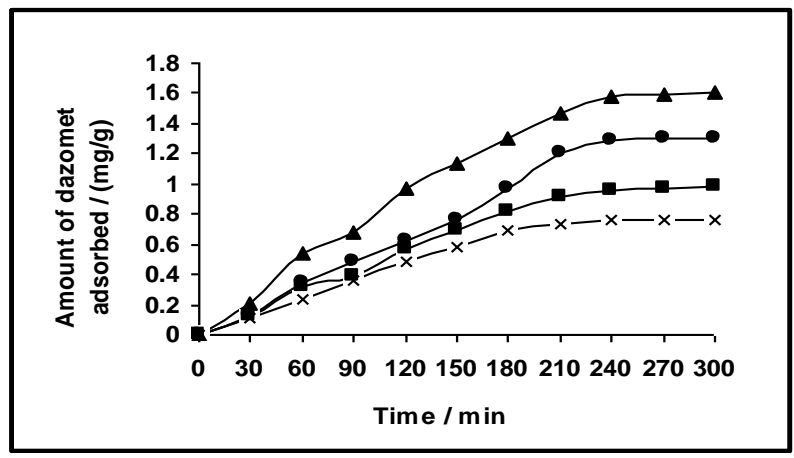

Fig (2): The variation of amount of dazomet adsorbed on kaolin clay with time in different concentration $\triangle 1 \times 10^{-4} \mathrm{~mol} / \mathrm{Liter} \bullet 8 \times 10^{-5}$ $\mathrm{mol} /$ Liter $\square 6 \times 10^{-5} \mathrm{~mol} /$ Liter $X 4 \times 10^{-5} \mathrm{~mol} /$ Liter.

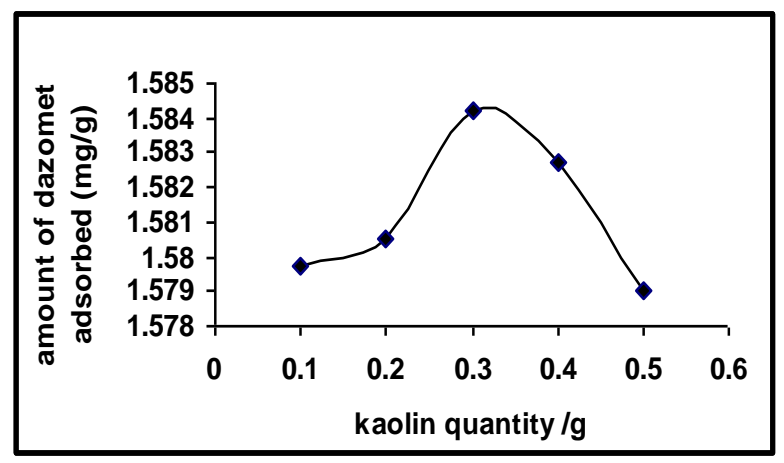

Fig (3):Amount of Dazomet adsorbed against kaolin clay quantity.

This indicates that the amount of dazomet adsorbed increase as the quantity of kaolin increased until $0.3 \mathrm{~g}$ and then it decreased. Therefore, the amount of kaolin used in all experiments is $0.3 \mathrm{~g}$

\section{Adsorption isotherm}

The adsorption isotherm obtained of the adsorption of dazomet on kaolin clay is illustrated in figure (4).

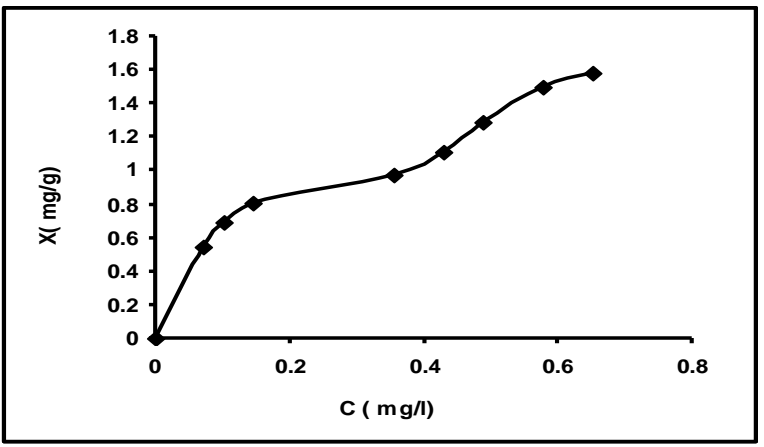

Fig (4): adsorption isotherm of dazomet on kaolin clay.

It was indicated that the isotherm was L-type according to the classification of Giles ${ }^{(17)}$.

This adsorption isotherm shows a high affinity type that is characterized by a plateau after an initial sharp increase in adsorption values. After the initial plateau region (which is corresponding to monolayer adsorption) the curve changed steadily and the second condensed monolayer was formed on the top of the first plateau. The dazomet molecule does not have the strong functional group $\mathrm{OH}$ and a 
strong affinity for hydrogen bonding in its molecular structure. Therefore, the adsorbents can adsorb the solute molecules of dazomet in planer configuration by means of non-hydrogen forces, as oriented flat in water- penetrated regions. Thus, an L-type curve is expected for the adsorption of dazomet from polar solvent ${ }^{(18)}$.

The Freundlich relationship was applied to experimental data obtained. The equation of Freundlich is ${ }^{(19)}$ :

$$
\mathrm{X}=\mathrm{K} \mathrm{C}^{1 / \mathrm{n}}
$$

Where $\mathrm{X}$, the amount of dazomet adsorbed per unit weight of kaolin $(\mathrm{mg} / \mathrm{g}), \mathrm{C}$, the equilibrium concentration in aqueous phase $(\mathrm{mg} / \mathrm{l})$. The constants $\mathrm{K}$ and $\mathrm{n}$ are Freundlich constants representing adsorption capacity and adsorption intensity respectively. The data obtained could be fitted to the following linearised Freundlich equation:

\section{$\log \mathrm{X}=1 / \mathrm{n} \log \mathrm{C}+\log \mathrm{K}$}

The results obtained are illustrated in figure(5), and shows that the adsorption data are in a good agreement with the Freundlich equation. Thus, it is evident that the multilayer adsorption takes place from solutions. It has a correlation coefficient $\left(\mathrm{R}^{2}\right)=0.97$ and calculated value of $\mathrm{K}$ and $\mathrm{n}$ are 2.709 and 3.94 respectively, obtained from the slope and intercept of the linear relationship between log $\mathrm{X}$ and $\log \mathrm{C}$. The results of $\mathrm{K}$ and $\mathrm{n}$ clearly show that the adsorption affinity value is high. This was expected because the solubility of Dazomet in water is relatively low ${ }^{(20)}$. The $\mathrm{K}$ value is low. This was due to the orientation of dazomet molecule on the kaolin surface which is reported to be in planar configuration if the solution is polar ${ }^{(15)}$.

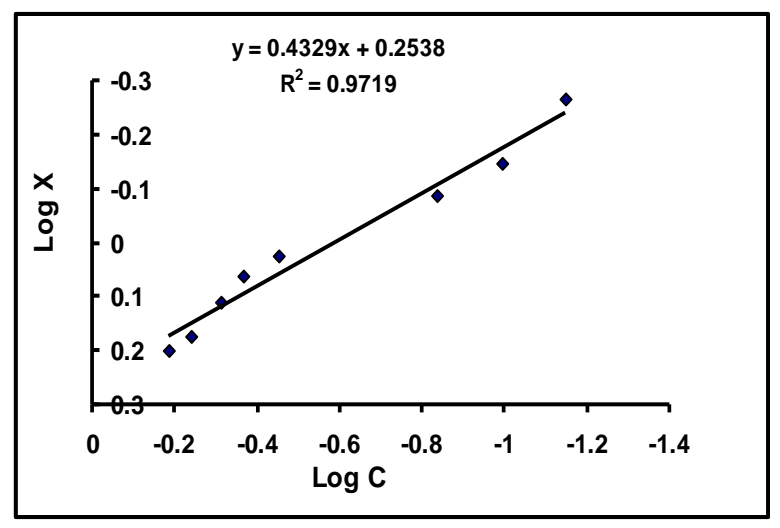

Fig.(5): The Freundlich linear relationship between $\log X$ and $\log C$ for the adsorption of dazomet on kaolin clay.

\section{Rate of adsorption}

The adsorption rates were obtained by taken a sample at a certain interval $(30,60,90,120$, $150,180,210$ and $240 \mathrm{~min}$ ) and dazomet concentration was determined by measuring the absorbance value of solutions. Then, the intial adsorption rates of different concentration of dazomet were determined on graphic by plotting the measured concentration versus time. The results obtained were illustrated in figure (6) which shows the concentration change of Dazomet in suspension versus time.

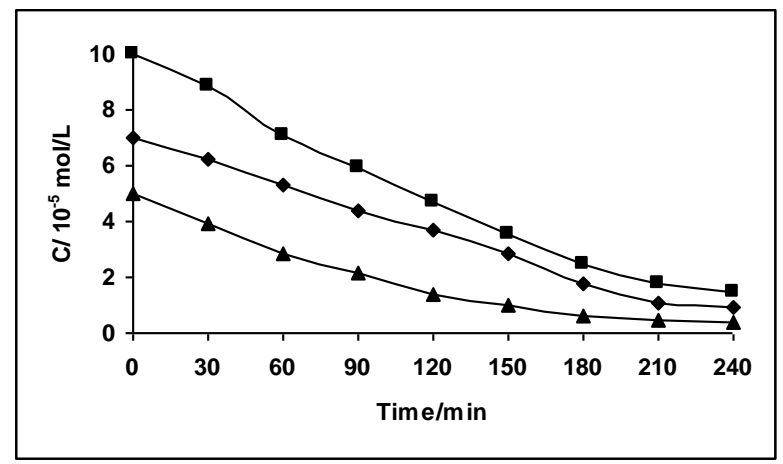

Fig (6): Plots of concentration of dazomet $(\mathrm{mg} / \mathrm{L})$ versus time. $\square 1 \times 10^{-4}(\mathrm{~mol} / \mathrm{L})$ $\checkmark 7 \times 10^{-5}(\mathrm{~mol} / \mathrm{L}) \Delta 5 \times 10^{-5}(\mathrm{~mol} / \mathrm{L})$.

The order of the adsorption process was predicated by fitting the first-order kinetics equation of,

$$
\ln \mathrm{A}_{\mathrm{o}}-\ln \mathrm{A}=-\mathrm{Kt}+\mathrm{I}
$$

where $\mathrm{A}_{\mathrm{o}}$; amount of adsorbed Dazomet at equilibrium , A; amount of adsorbed dazomet in 
time , I; the integration constant, $\mathrm{t}$; the time in minutes and $\mathrm{K}$; rate constant.

The plot of $\left(\log \mathrm{A}_{0^{-}} \mathrm{A}\right)$ versus time of adsorption of dazomet on kaolin clay shows a straight-line behavior (figure 7). This suggests the first-order kinetics of the adsorption process. Then, the value of specific rate constant was determined from the slope of straight line. The result obtained indicated that the value of $\mathrm{K}$ is $1.358 \times 10^{-2} \mathrm{~min}^{-1}$.

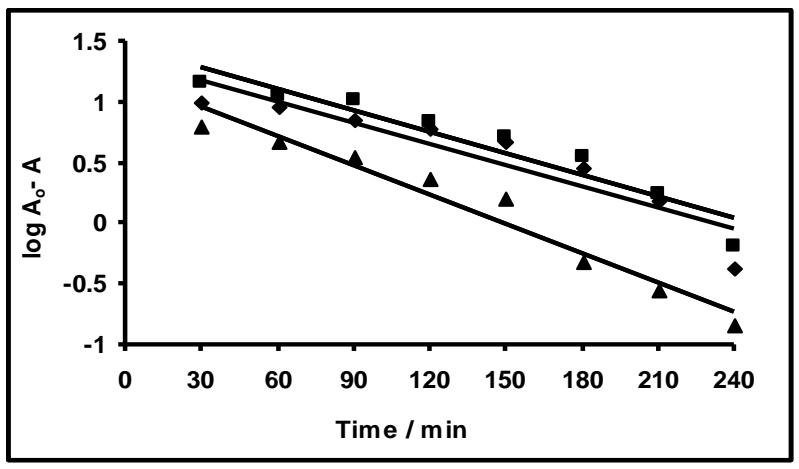

Figure (7): first order plot of adsorption of dazomet on kaolin clay. $\log A_{o}$-A against time/ min. . $1 \times 10^{-4}(\mathrm{~mol} / \mathrm{L})$

$\checkmark 7 \times 10^{-5}(\mathrm{~mol} / \mathrm{L}) \triangle 5 \times 10^{-5}(\mathrm{~mol} / \mathrm{L})$.

As known, the adsorption of solute from solution involve three steps ${ }^{(21)}$, in first step, bulk transport of solute in solution is rapid. In the second step, film transport covers diffusion of solute through of a hypothetical film boundary layer. In the third step, the solute diffuse within the pore volume of the adsorbent and along pore- wall surfaces to an active adsorption site. Film transport is the major factor controlling the rate of adsorption from solution onto porous adsorbent. The adsorption process is controlled by film diffusion when the rate of adsorption changes linearly with concentration (22). The effect of initial concentration of dazomet on the adsorption rate is shown in figure (8).

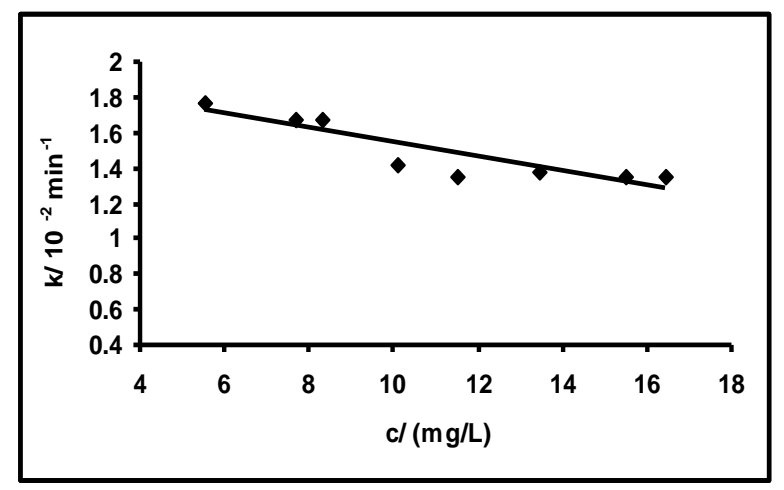

Fig (8): Plot of $K$ versus initial concentration of dazomet at $30 C^{\circ}$.

The adsorption rate decreased linearly with the initial concentration. It is evident that the adsorption is controlled by a film diffusion mechanism $^{(15)}$.

\section{Conclusions:-}

From the results obtained, it can be concluded the following:-

1- The adsorption isotherm form was L-type according to the classification of Gile.

2- Adsorption of dazomet was found to conform to Freundlich equation, which evident that the multilayer adsorption takes place from solutions.

3- The adsorption rate was found to fit the firstorder of kinetics equation and the adsorption process was controlled by a film diffusion mechanism.

\section{References:}

[1] Gunasekara, A.S. and B. Xing, 2003. Sorption and desorption of naphthalene by soil organic matter: Importance of aromatic and aliphatic components. J.Environ. Qual., 32: 240-246.

[2] Liselotte, C and Ida. F, 2001. Atrazine, Iso proturon, Mecopro, 2,4-D- and Bentazone Adsorption onto Iron oxide. J. Environ. Qual, 30: 858-869.

[3] Deer, W.A., Howi, R.A., and Zussman, J. (1992) An introduction to the rock- forming minerals $\left(2^{\text {nd }}\right.$ ed) Harlow: longman ISBN 0582- 30094-0. 
[4] Reynolds JEF. Martindale, 1989. The Extra Pharmacoppea,. 29 ed. London: The Pharmaceutical Press, p 1092.

[5] Onyekwelli, A.O., Usifoh, C.O., Okunrobo. L.O and Zuofa, J.D,(2003) Adsorptive property of kaolin in some drug formulations. Tropical Journal of Pharmaceutical Research. 2(1): 155-159.

[6] Worral, F.., A.Parker., J.E. Rae, and A.C. Johnson. 1996. Equlibrium adsorption of isoproturon on soil and pure clays. Eur. J. Soi Sci, 47: 265-272.

[7] Sannino, F., A.Violante, and L.Gianfreda. (1997). Adsorption- desorption of 2,4- D by hydroxy aluminum montomorillionite complexes. Pestic. Sci. 51: 429-435.

[8] Moreau-Kevan, C., and C. Mouvet. (1998). Adsorption and desorption of atrazine, deethyl atrazine, and hydroxyl atrazine by soil components. J. Environ. Qual. 27: 4653.

[9] Celis, R., M.C. Hermosin, L.Cox and J.Cornejo. (1999). Sorption of 2,4dichlorophenoxyacetic acid by model partricles simulating naturally occurring soil colloids. Environ. Sci. Tecnol. 33: 12001206.

[10] Calusen, L., Fabricius, I and Madsen, L. 2001. Adsorption of pesticides onto quartz, calcite, kaolinite, and $\alpha$ - alumina. J. Environ. Qual. 30: 846-857.

[11] Gred U. Blace, Natalia A. Kulikova, Sebastain Hesse, Frank- Dieter, Kopinke, Irina V. Perminova, and Fritz H. Frimmel. 2002, adsorption of Humic Substances onto kaolin clay Related to their structural Features, Soil Sci. Soc. Am. J. 66: 18051812.

[12] Ahmes F. El. Aswad, 2007, Effect of organic Amendments on Aldicarb sorptiondesorption and soil- Bound Residue, J. Applied Sciences Research. 3(11) 14371448.

[13] Taher. S. A, 2007, Experimental and theoretical study of environmental pathway degradation for pesticides pollution propanil and dazomet. Ph.D. thesis. University of

Baghdad, college of science for women, $\mathrm{p}(56)$.

[14] FAO (2001) Specifications and evaluations for plants protection products.

[15] T.Sismanoglu, A. Eveag, S.Pura and E. Ercag, 2004. Kinetics and isotherms of dazomet adsorption on natural adsorbents. J. Braz. Soc., (15): 669-675.

[16] Trckova, M., Matillova, L., Dvorsk, L and Pavli, I. 2004. Kaolin, bentonite, and zeolites as feed supplements for animals: health advantages and risks. Vet. Med. Czech, (10): 389-399.

[17] Giles, C.H., T.H. MacEwan, S.N.Nakhwa, and D.Smith. 1960. Studies in adsorption. Part XI. A system of classification of solution adsorption isotherms, and its use in dignosis of adsorption mechanism and measurement of specific surface areas of solids. J. Chem. Soc. 3: 3973-3993.

[18] Guangyu, Y., Thiruvenkatachri, V.2003; Water Research, 37, 4486.

[19] Adamson, A.W. 1997. "Physical chemistry of surfaces" $6^{\text {th }}$ ed. John Wiley and sonns,Inc.: New York; 394

[20] Khouloud A.A., Wasfi. M.O and Naji, M.N. 2001. Adsorption of Allopurinol and Ketotifen by Chitosan. AADS Pharm Sci Tech. 2(1) article 3.

[21] Siejko, F.L. 1985; Adsorption Technology; Marcel Dekker: New York.

[22] Atun, G. and Sismanglu, T. 1996; J. Environ. Sci. Health, A31, 2055.

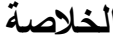

$$
\begin{aligned}
& \text { في هذا البحث، تم دراسة الامتزاز لمبيد الدازومت من } \\
& \text { المحاليل المائية على سطح اطيان الكاؤولين بدرجة حرارة }
\end{aligned}
$$

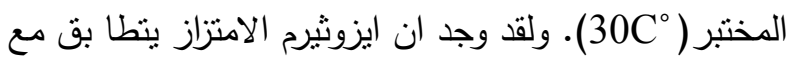

$$
\begin{aligned}
& \text { ايزو ثيرم فرندلج الخاص بالامنزاز متعدد الطبقات. وقد نم } \\
& \text { التحري عن نا ثير كل من التز كيز و الزمن على عملية } \\
& \text { الامتزاز •. ودلت الدراسة على ان سرعة امتزاز مبيد الدازومت } \\
& \text { تتطابق مع المعادلة الحركية للمرتبة الاولى، وكذللك وجد ان } \\
& \text { سرعة الامتزاز تقل خطيا مع التركيز الابتدائي للمبيد وهذا يعني } \\
& \text { ان الخطوة المحدة للسرعة هي خطوة الانتشار . }
\end{aligned}
$$


